\title{
The Influence of Network Quality of Service Factors on the Usability and Effectiveness of Multimedia Internet Broadcasting
}

Link to publication record in Manchester Research Explorer

Citation for published version (APA):

Procter, R., McKinlay, A., Gallacher, S., Sloane, A. (Ed.), \& Lawrence, D. (Ed.) (2001). The Influence of Network Quality of Service Factors on the Usability and Effectiveness of Multimedia Internet Broadcasting. In Multimedia Internet Broadcasting: Quality, Technology and Interface (pp. 35-52). Springer Nature.

Published in:

Multimedia Internet Broadcasting: Quality, Technology and Interface

\section{Citing this paper}

Please note that where the full-text provided on Manchester Research Explorer is the Author Accepted Manuscript or Proof version this may differ from the final Published version. If citing, it is advised that you check and use the publisher's definitive version.

\section{General rights}

Copyright and moral rights for the publications made accessible in the Research Explorer are retained by the authors and/or other copyright owners and it is a condition of accessing publications that users recognise and abide by the legal requirements associated with these rights.

\section{Takedown policy}

If you believe that this document breaches copyright please refer to the University of Manchester's Takedown Procedures [http://man.ac.uk/04Y6Bo] or contact uml.scholarlycommunications@manchester.ac.uk providing relevant details, so we can investigate your claim.

\section{OPEN ACCESS}




\title{
THE INFLUENCE OF NETWORK QUALITY OF SERVICE FACTORS ON THE USABILITY AND EFFECTIVENESS OF MULTIMEDIA INTERNET BROADCASTING
}

\author{
Andy McKinlay ${ }^{1}$, Rob Procter $^{2}$ and Scott Gallacher ${ }^{3}$ \\ ${ }^{1}$ Department of Psychology \\ University of Edinburgh \\ Edinburgh, EH8 9JZ, Scotland \\ Tel: +44131650 4643 \\ Email:a.mckinlay@ed.ac.uk \\ ${ }^{2}$ Institute for Communicating and Collaborative Systems \\ Division of Informatics \\ University of Edinburgh \\ Edinburgh, EH1 1HN, Scotland \\ Tel: +441316502707 \\ Email:rnp@dai.ed.ac.uk \\ ${ }^{3}$ Research Centre for Social Sciences \\ University of Edinburgh \\ High School Yards \\ Edinburgh EH1 1LZ, Scotland \\ d.s.gallacher@sms.ed.ac.uk
}

\begin{abstract}
While many businesses are keen to develop multimedia internet broadcasting for in-house services, their deployment raises important practical issues, both for user departments and for corporate network managers. These range from fitness for purpose and usability on the one hand, to the implications for network infrastructure on the other. The study we outline in this paper was motivated by the need to address these issues.

We describe an experimental evaluation of a multimedia internet broadcasting service designed to support staff training within a large UK bank. The focus of our investigation is the influence of different kinds of media content and of network quality of service upon subjects' memory for, and comprehension of, information. In particular, our findings are that degraded quality of service has a greater influence on subjects' uptake of emotive/affective content than on their uptake of factual content. In general, we found that subjects rated the usability of the system to be quite low, even under ideal network conditions. The results have implications for the more general application of multimedia internet broadcasting.
\end{abstract}




\section{Keywords}

Multimedia usability, network quality of service, training, vicarious learning, affective communication

\section{INTRODUCTION}

We report here the results of two experimental studies in which we evaluated the usability of multimedia internet broadcasting in a training application and investigated the effects of network quality of service (QoS) on subjects' capacity to assimilate the factual and emotional content. ${ }^{1}$

Many companies are now becoming interested in the use of multimedia, internet-based broadcasting as a staff training and general information aid. With Web-based presentation tools, text, graphics, audio and video can be easily combined to serve a diverse range of business communication applications and content. The use of such media has already demonstrated its worth in distance learning and related applications [12]. For corporate network managers, however, the spread of these applications represents an additional -- and as yet largely unquantified -- load on company intranets that are typically expected to support a wide variety of communications services. It would simply be unacceptable for new traffic to degrade other services; equally, if it is necessary to add extra network capacity, then the question is how much, and would the investment deliver the desired results? It is essential to consider, therefore, what combinations of media content may provide the most effective solutions to business communications needs, and to characterise their network QoS requirements. In turn, this may involve examining how factors such as network bandwidth effect users' perceptions of multimedia internet broadcast quality and acceptability, and its effectiveness for specific applications.

The problems inherent in the use of public, packet-switched communications networks for real-time data transmission are, of course, well-known [2]. They give rise to numerous effects that may influence the 'watchability' of multimedia internet broadcasting. These include the delay or loss of frames, audio clarity, lip synchronisation during speech, and a general perturbation of the relationship between the visual and auditory components [1]. Little is known, however, of how the impact of these effects is perceived by users [4,7]. Previous studies have suggested that different types of video information may have different requirements [1]. Part of our aim in these studies was to investigate what influence the dynamic fluctuations in network bandwidth of typical of shared packet-switched

\footnotetext{
${ }^{1}$ An earlier, shorter account of this work was published in [9].
} 
networks might have on usability, especially in relation to the visual and nonverbal, vocal communication channels.

An investigation of the usability of multimedia internet broadcasts and, in particular, the influence of network QoS on users' perceptions of quality will assist in informing minimum QoS requirements and in the drawing up of guidelines for multimedia content creation and selection. For example, it may be the case that multimedia materials created for a specific form of delivery such as broadcast TV are not as effective when delivered via the internet.

\section{AFFECTIVE CONTENT AND COMMUNICATION}

Social psychologists have claimed [3] that affective information is conveyed to a large extent by non-verbal information of the sort which is carried in the visual and non-verbal, vocal channels, where 'affect' refers to temporary emotional states such as mood or more stable emotional states such as aspects of personality. When these channels are inhibited, or unavailable, inter-personal communication may become more problematic. For example, email communication between friends is susceptible to misjudgements of mood due to the absence of non-verbal information that in an everyday conversation would alert the hearer to the speaker's intentions. Similarly, email communication between strangers may be susceptible to mis-judgements of more stable affective factors such as those deriving from personality. Such problems may explain, for example, the prevalence in email communication of the overt inclusion of extra content that helps clarify affective tone (e.g., smileys or ironic commentary).

The foregoing implies that even a relatively minor degradation of the visual channel may impact upon the extent to which people perceive affective information in inter-personal communication. Specifically, it can be hypothesised that the degradation of the visual channel will reduce nonverbal signals, which will, in turn, reduce the extent to which people are willing to ascribe emotional overtones to a scene.

Such effects may have significant implications for multimedia internet broadcasting in general, and for the design of usable multimedia materials intended for application in e.g., vicarious learning [6] and multimedia learning environments (MLEs) [11] in particular. Vicarious learning refers to the re-use of people's experiences as a learning aid for others. It exploits our capacity to learn by watching other people, e.g., the ways in which other people solve problems. In such circumstances, both factual and affective information may be important for the audience's understanding.

Vicarious learning seeks to allow the audience to share as much as possible of the original learning situation that they are observing. It follows that the audience needs to be able to understand fully the communicative background of the original learning setting which they are vicariously 
experiencing, including its affective aspects. However, if e.g., network QoS factors lead to the degraded transmission of affective information, this may adversely affect the audience's capacity to make affective judgements relevant to their understanding of the content. Consequently, combining vicarious learning approaches with network-based delivery may present new challenges, for both the design of the multimedia learning materials and for the network services employed in their transmission.

In addition from a more general usability evaluation, therefore, a particular aim of our study was to explore the effects of network QoS on an audience's comprehension of affective information carried in the visual channel.

\section{BACKGROUND}

We are involved in a long-term study a number of multimedia projects (including video conferencing and WWW) within Scottish Bank ${ }^{2}$, a large UK bank. Our investigations are based around detailed case studies of the development and adoption of the technology [10]. One area of great interest for the bank at the present time lies in the delivery of training materials to staff over the bank's internal digital network.

Currently, much of the bank's staff training and more general briefing activities are carried out using the bank's own internal TV network. Presentation formats commonly used include full screen captions with voiceovers and short video segments of presenters. The bank's Learning Technologies Group, who are responsible for meeting the bank's training requirements, were keen to discover whether training materials could be delivered in a usable form over the bank's digital network. If this is feasible, then the options available for the style and management of training become significantly increased. Scottish Bank's network managers and IT strategists, on the other hand, were equally keen to discover to what extent this new application would require additional investment in network technologies and infrastructure.

In order to begin to answer these questions, we devised an experimental study of the influence of media content and network QoS on subjects' recall and comprehension of the contents of multimedia internet broadcasts. Having considered the issues discussed in the previous section, we decided to focus in particular on the effects of QoS on affective information uptake.

The limitations of laboratory studies as a technique for investigating users' requirements for IT systems are now widely known and acknowledged. User requirements must be contextualised to be properly

\footnotetext{
${ }^{2}$ The names of people and companies have been anonymised.
} 
understood; they also cannot be assumed to be fixed, but are subject to change as users learn and adapt to new technologies and their specific affordances. We argue, however, that laboratory studies have a role to play in helping formatively to map out the design space and to assess the potential impact of design options.

\section{NETWORK SIMULATION}

The goal of the network simulation was to allow for setting different levels of packet loss. The simulation topology was chosen to duplicate Scottish Bank's intranet characteristics as far as was reasonably possible. This was imperative if the experimental results were to have a direct relevance for the bank's network managers, but, as we see below, did lead to some problems in generating controllable QoS effects.

The simulation consisted of two $4 \mathrm{Mbs}$ token rings connected by a router. A Windows NT Server was connected to one token ring and two client workstations connected to the other so that packets transmitted by the server had to pass through the router before being received by the clients. In addition to the multimedia broadcast server and client workstations, there were two background traffic generators that could be configured to generate arbitrary loads on the network. One load generator was connected to the same token ring on which the multimedia server was located; the other was connected to the router through a $10 \mathrm{Mbs}$ Ethernet. All token ring stations were set to operate without priority. The simulation network is shown in Figure 1.

To investigate the effect of network congestion on multimedia internet broadcast service usability it was necessary to be able to simulate traffic conditions such that total bandwidth demands exceeded network capacity, thus constraining the multimedia broadcasts to work under less than optimal bandwidth conditions. In such circumstances, where a network service is operating under a real-time transmission protocol with no re-transmission, a loss of packets would be inevitable, leading to a lower overall end-to-end QoS. The behaviour of token ring networks complicates the achievement of such controllable bandwidth conditions, however. A fundamental characteristic of the token ring is fairness, so it is difficult to manipulate traffic conditions such that unfairness results. The consequence is an unstable operating characteristic that is difficult to control and a QoS that tends to degrade very quickly as overall network traffic increases. 